\title{
Youth Perspective Towards LGBT's Behavior Based on Gender: Implications on Social Work
}

\author{
M S N Abu Hassan ${ }^{1 *}$, A Ab Halim ${ }^{1}$, A B H M Maliki ${ }^{1}$, Kalfin $^{2}$ and S H Yuningsih ${ }^{3}$
}

\author{
${ }^{1}$ Faculty of Applied Social Science, University Sultan Zainal Abidin, Terengganu, Malaysia. \\ ${ }^{2}$ Doctor Program of Mathematics, Faculty of Mathematics and Natural Sciences, Universities Padjadjaran, Indonesia \\ ${ }^{3}$ Master Program of Mathematics, Faculty of Mathematics and Natural Sciences, Universities Padjadjaran, Indonesia \\ *Corresponding author. E-mail: nizamhassan@unisza.edu.my
}

\begin{abstract}
Transsexual phenomena in Malaysia are considered as symptoms of gender disruption or identity crisis in which the individual has a behavior that is contrary to the norm of a person's normal life. This situation has made the community less accepting of the transsexual and even a scorn for some people because they are considered to have deviated from the norms of society. This study conducted on undergraduate students across Malaysia. The main aim of this study was to identify the association between gender factors among youths influences stigma and discrimination against LGBT people and to identify gender factors through adolescents affect the awareness level of acceptance of the issue of LGBT group acceptance in the social system. In addition, this study also aimed to identify whether Social Work interventions are appropriate for enhancing youth understanding in reducing LGBT-related risks. The selected study locations are throughout Malaysia. The research data were quantitatively obtained through the questionnaire method. The questionnaire was distributed randomly to 1200 respondents comprising undergraduate students throughout Malaysia. Questionnaires were divided into sections such as respondents' demographics, lesbian perceptions and gay perceptions. The statistical analysis used in this study was ANOVA. The findings show that there is a youth perspective on LGBT behavior based on gender and the implications for social work. Through the results of this study, several appropriate suggestions and interventions by social workers have been put forward by researchers for improvement to address LGBT issues.
\end{abstract}

Keywords: LGBT, Gender, Malaysia Youth

\section{INTRODUCTION}

Sexual orientation or sexual attraction is the desire of the individual to fulfill the love and intimacy that creates a bond between two people. Sexual orientation is not just physical or biological, but it also extends to spiritual or inner relationships [1]. This is closely linked to the growing LGBT issue in Malaysia. However, some of the findings of the study indicate two conditions; sexual orientation can change and sexual orientation cannot change [2]. Sexual orientation is still a mystery among scientists. They discover the fact that biological factors, whether genetic, DNA or other, and environmental influences especially in early childhood have an influence on sexual orientation. Based on that statement, we do not need to be politically correct about whether or not the sexual orientation can be altered, either from birth or during puberty. Everyone experiences different situations so that a general conclusion cannot be made. Sexual orientation is something unique and needs to be handled wisely by each individual [3]. This understanding also serves as a guide for social workers in Malaysia taking into account the factors of cultural and socio-economic diversity. Social work practices in Malaysia were also guided by the National Welfare Policy (1990) which emphasized the importance of social work in promoting social harmony and stability, strengthening and enhancing the functioning of family institutions and thus fostering a caring society. Efficient social workers must provide services to individuals, 
families, groups, communities and systems related to the LGBT environment itself [4].

\section{METHODOLOGY}

\subsection{Participants}

The current research consists of 1095 male and female respondents range from ages of 18-32 $( \pm 1.5)$ years old. The selection of samples for this method of study is randomly chosen from a recognized population. The sample consisted of 597 male and 498 female respondents. The researcher used a quantitative method of study that leads to the perceptions of youth. The respondents are among the students from all universities in Malaysia and comprises from different gender in Malaysia. A descriptive approach through review methods of survey widely used in research is to collect data and information obtained from the respondents [5][10]. This instrument is used to identify the level of discrimination among the youths against the LGBT behavior.

\subsection{Instrument}

In this study, measurement scales are used in instrumentation to see the perspective of youth towards the behavior of LGBT in different gender. A questionnaire is the main instrument in gathering information from respondents. This instrument is a threepart questionnaire. Part $\mathrm{A}$ is the demographic of respondents and part B has 10 questions about Malaysian adolescents' perception of lesbians. Whereas section C has 10 questions about adolescents' perceptions of gay people. In using this scale, respondents are required to mark one of the scales in the questionnaire form. The scale of the questionnaire in the questionnaire was $1=$ strongly disagree, $2=$ strongly disagree, $3=$ uncertain, 4 $=$ agree, $5=$ strongly agree. By choosing one of the answers from the scale of the survey, respondents' responses were reflected in Malaysia's youth perspective on LGBT behavior based on gender.

\subsection{Statistical Analysis}

Pre-processing data: (20 variable x 1095 databases) was calculated in this study. According to the overall data used, there are matrix with little data missing $(\sim 3 \%)$. This research is focusing on the youth perspective towards LGBT's behavior based on gender: implications on social work. Analysis of Variance (ANOVA): enable the researcher to investigate and answer a vast array of research questions. It is very useful when designing and analyzing experimental behavioral science research [11]. This research suggests that, ANOVA test method is a corresponding method in evaluating youth's perception.

\section{RESULTS AND DISCUSSION}

The Table 1 shows that there are only two significant questions B6 with $\mathrm{F}=4.68$ and $\mathrm{Pr}=\mathrm{F} 0.03$ while $\mathrm{B} 7$ has $\mathrm{F}$ $=6.43$ and $\mathrm{Pr}=\mathrm{F} 0.01$. Besides. $\mathrm{B} 1$ shows $\mathrm{F}$ equals 0.56 and $\mathrm{Pr}=\mathrm{F}$ values 0.45 followed by $\mathrm{B} 2$ denotes $\mathrm{F}$ equals 0.03 and $\mathrm{Pr}=\mathrm{F}$ equals 0.45 . Subsequently B3 records an $\mathrm{F}$ value of 0.82 and a $\operatorname{Pr}=F$ value of 0.87 . B 4 has $F$ value of 0.11 and $\mathrm{Pr}=\mathrm{F}$ value of 0.74 while $\mathrm{B} 5$ has $\mathrm{F}$ value of 1.70 and $\mathrm{Pr}=\mathrm{F}$ value of 0.19 . Furthermore, $\mathrm{B} 8$ has an $\mathrm{F}$ value of 1.02 and a $\mathrm{Pr}=\mathrm{F}$ value of 0.31 while $\mathrm{B} 9$ has an $\mathrm{F}$ value of 0.21 and a $\operatorname{Pr}=\mathrm{F}$ value of 0.66 . Finally, B10 expresses a $F$ value of 1.52 and a $\operatorname{Pr}=F$ value of 0.22 . All of the above are $\mathrm{B} 1, \mathrm{~B} 2, \mathrm{~B} 3, \mathrm{~B} 4, \mathrm{~B} 5, \mathrm{~B} 8, \mathrm{~B} 9$ and $\mathrm{B} 10$ are not significant.

Table 1 Statistical inference analysis of part B questions

\begin{tabular}{lccc}
\hline Item & $\mathrm{F}$ & $\operatorname{Pr}=\mathrm{F}$ & Significant \\
\hline B1 & 0.56 & 0.45 & No \\
B2 & 0.03 & 0.87 & No \\
B3 & 0.82 & 0.37 & No \\
B4 & 0.11 & 0.74 & No \\
B5 & 1.70 & 0.19 & No \\
B6 & 4.68 & 0.03 & Yes \\
B7 & 6.43 & 0.01 & Yes \\
B8 & 1.02 & 0.31 & No \\
B9 & 0.21 & 0.66 & No \\
B10 & 1.52 & 0.22 & No \\
\hline
\end{tabular}

The Table 2 shows that there are only two significant questions that are $\mathrm{C} 5$ with $\mathrm{F}=4.33$ and $\mathrm{Pr}=\mathrm{F}$ values 0.04 and $\mathrm{C} 10$ shows $\mathrm{F}$ values of 7.72 and $\mathrm{Pr}=\mathrm{F}$ values of 0.01. Besides. $\mathrm{C} 1$ shows an $\mathrm{F}$ value of 1.89 and a $\mathrm{Pr}=$ $\mathrm{F}$ value of 0.17 followed by a $\mathrm{C} 2$ that shows an $\mathrm{F}$ value of 0.01 and a $\mathrm{Pr}=\mathrm{F}$ value of 0.93 . Subsequently $\mathrm{C} 3$ recorded an $\mathrm{F}$ value of 0.51 and $\mathrm{a} \operatorname{Pr}=\mathrm{F}$ value of 0.48 . $\mathrm{C} 4$ has a F value of 1.68 and a $\mathrm{Pr}=\mathrm{F}$ value of 0.20 while C6 has a $F$ value of 0.83 and a $\operatorname{Pr}=F$ value of 0.36 . Furthermore, $\mathrm{C} 7$ has an $\mathrm{F}$ value of 2.10 and a $\mathrm{Pr}=\mathrm{F}$ value of 0.15 while $\mathrm{C} 8$ has an $\mathrm{F}$ value of 2.01 and a $\mathrm{Pr}=$ $F$ value of 0.16 . Finally, $C 9$ expresses a $F$ value of 1.61 and a $\mathrm{Pr}=\mathrm{F}$ value of 0.21 . All of the above are $\mathrm{C} 1, \mathrm{C} 2$, C3, C4, C6, C7, C8 and C9 are not significant.

LGBT is no longer something we hear often in this modern age, it is even more worrying for many as an example of society. People are becoming increasingly uncomfortable with the existence of this group of people who are increasingly daring to express themselves in various ways, such as on social networking sites. In community life, a person who does not obey the rules of society will be removed from the society. This is because they will cause problems in society. LGBT people or members of the community who are involved with LGBT will be exposed to society because it is feared that it will influence other people to join them [12]. If this happens, 
the community involved will be disgraced and the honor of the community will be diminished. This LGBT issue is not a social issue but it will have a devastating effect on the perpetrator or the individual involved. This is because the individual does not recognize their abilities and advantages. They also become indifferent to themselves and try to change their physical or mental identity at the same time [13].

Table 2 Statistical inference analysis of part C questions

\begin{tabular}{lccc}
\hline Item & $\mathrm{F}$ & $\mathrm{Pr}=\mathrm{F}$ & Significant \\
\hline C1 & 1.89 & 0.17 & No \\
C2 & 0.01 & 0.93 & No \\
C3 & 0.51 & 0.48 & No \\
C4 & 1.68 & 0.20 & No \\
C5 & 4.33 & 0.04 & Yes \\
C6 & 0.83 & 0.36 & No \\
C7 & 2.10 & 0.15 & No \\
C8 & 2.01 & 0.16 & No \\
C9 & 1.61 & 0.21 & No \\
C10 & 7.72 & 0.01 & Yes \\
\hline
\end{tabular}

Discrimination can also have a negative impact on the individual [14]. This is because the stigma of society underestimating this group will certainly be detrimental to the group. The service you provide will not be the same as in the normal community. This has led to indirect discrimination against LGBT people [15]. This will also have a profound effect on the individual and the perception that the community does not understand the soul and encourage the unprofitable things. Islam is a organized and systematic religion. It shapes the way of human life with the best of rules, whether it involves human relations with Allah or human relations with other humans. The practice of Islamic law established by Allah is clearly for the sake of the ummah, invoking the good and rejecting any form of disobedience. Allah swt as the One creator has established a living law that is in accordance with the nature of man and the essence of their soul. However, in recent times there has been a tendency for sexual aggression to be seen to be more aggressive and clearly deviated from the rules of nature established by Islam. This tendency is translated into a simple expression of LGBT. Islam, clearly rejects LGBT and Muslims view it as a major sin because there are many passages from Quranic verses and hadiths that examine this act. Basically, this human being was created by Allah SWT clearly his gender, male and female and he was created in pairs. In the case of sexuality, it is referred to as khiye. As the saying of Allah swt says, "Then Allah made from it a pair: male and female (alQiyāmah: 39).

In conclusion, this issue of LGBT practice of inverse lifestyle needs to be addressed in various ways, if the issue continues then there may be an increasing number of young people out there who will also be involved in this problem [16]. These people not only do things that are not normal but they also respect the institution of family, religion and moral aspects [17]. As a result of this negative culture, the destruction of the social system will result in a conflict of values and customs of the eastern culture [18]. In order to develop and maintain good values, children exposed to LGBT symptoms should not be excluded and excluded. They need to pay enough attention to convince them that what they are doing is wrong. Family institutions are seen as the most important agents for this group. AIDS became a major concern when, on June 5, 1981, doctors began describing a rare, often fatal, infectious lung epidemic among five homosexuals in Los Angeles [19]. Since then, AIDS and homosexuality have become like that. In the early days of the disease, San Francisco was the worst infected gay community, with almost half of its homosexual population infected.

Now after the decline in the rate of AIDS infections among homosexuals in recent years, the rise in AIDS has increased among gay people through public baths, a popular spot for gay men seeking free sex, now a leading cause of the spread of AIDS among homosexuals. Increased rates of HIV infection in the country are generally contributed by some groups. In fact, reports released by the Malaysian AIDS Council and the AIDS Foundation Malaysia (2017) show that HIV infection is largely contributed by 42 percent of heterosexual people [20]. The report also shows that homosexuals and bisexuals account for 36 percent of HIV infections, followed by injecting drug users by 17 percent. HIV transmission from mother to child and other means of infection recorded the lowest percentage of 4 percent and 1 percent. This report clearly shows that there are several key factors contributing to the increasing number of HIV infections in the country. In addition, things are becoming more serious as most conditions in the Asia Pacific region do not have health care services and HIV prevention programs for MSM [21]. This is obviously a worrying issue if left untouched and unobtrusive. Indeed, there have been various interventions undertaken by the government and non-governmental organizations (NGOs) in addressing HIV issues in the country. Among the interventions included the implementation of the Harm Reduction Program. The Harm Reduction Program is an approach adopted by the government in reducing harm to HIV, hepatitis B and C infections while sharing syringes [22]. The approach of the program is also to reduce the harm of overuse of drugs through injection, as well as crime due to drug addiction [23].

\section{CONCLUSION}

As a result of this study, researchers were able to identify gender factors contributing to Malaysian youth's perception of LGBT behavior. This is an LGBT-related issue that has led to cultural misunderstandings and the fight against the current. Human services may be defined 
as those systems of services and allied occupations and professions that concentrate on improving or maintaining the physical and mental health and general well-being of individuals, groups, or communities in our society [24]. Those who choose and are trapped in this inverse culture have obviously done something that is not normal and does not respect the institution of family, religion and moral aspects. As a result of this negative culture, the destruction of the social system will result in a conflict of values and customs of the eastern culture. There are many social worker roles that can counteract the perception of LGBT youth on gender-based LGBT behavior among LGBT people [25]. This role helps to shape their personalities where they serve as a guide in providing good service to LGBT people who want to change. This is because, young people who exhibit good behavior can be highly motivated in any change they want to make [26]. Therefore, social workers need to guide the behavior of youth in providing good services to achieve universal harmony where good social systems need to be filled by everyone to carry out their functions.

\section{ACKNOWLEDGMENT}

This research was supported by University Sultan Zainal Abidin, Faculty of Applied Social Science. We thank our colleagues and lecturer from Dr. Mohd Syaiful Nizam Bin Abu Hassan who provided insight and expertise that greatly assisted the research, although they may not agree with all of the interpretations/conclusions of this paper.

\section{REFERENCES}

[1] E. Michopoulou, P. Jauniškis. Exploring the relationship between food and spirituality: A literature review. International Journal of Hospitality Managemen t, 87 (2020) 102494. DOI: https://doi.org/10.1016/j.ijh m.2020.102494

[2] H. Panter. Transgender cops: The intersection of gender and sexuality expectations in police cultures. Routledge. 2018.

[3] S. L. Samons. Can this marriage be saved? Addressing male-to-female transgender issues in couples therapy. Sexual and Relationship Therapy, 24 (2) (2009) 152-162. DOI: https://doi.org/10.1080/14681 990903002748

[4] N. Van Den Bergh, C. Crisp. Defining culturally competent practice with sexual minorities: Implications for social work education and practice. Journal of Social Work Education, 40 (2) (2004) 221-238. DOI: https://doi.org/10.1080/10437797.2004.10778491
[5] M. J. Kennish. Estuarine research, monitoring, and resource protection. CRC Press.2003.

[6] K. F. Balsam, Y. Molina, B. Beadnell, J. Simoni, K. Walters. Measuring multiple minority stress: the LGBT People of Color Microaggressions Scale. Cultural Diversity and Ethnic Minority Psychology, 17 (2) (2011) 163. DOI: https://doi.org/10.1037/a0023244

[7] A. Padrón-Cabo, E. Rey, A. Kalén, P. B. Costa. Effects of training with an agility ladder on sprint, agility, and dribbling performance in youth soccer players. Journal of human kinetics, 73 (1) (2020) 219228. DOI: https://doi.org/10.2478/hukin-2019-0146

[8] J. Fett, A. Ulbricht, A. Ferrauti. Impact of physical performance and anthropometric characteristics on serve velocity in elite junior tennis players. The Journal of Strength \& Conditioning Research, 34 (1) (2020) 192-202. DOI: https://doi.org/10.1519/JSC.0000000000 002641

[9] C. Sabina, J. Wolak, D. Finkelhor. The nature and dynamics of Internet pornography exposure for youth .Cyber Psychology \& Behavior, 11 (6) (2008) 691-693. DOI: https://doi.org/10.1089/cpb.2007.0179

[10] D. Hammond, F. Kin, A. Prohmmo, N. Kungskulniti, T. Y. Lian, S. K. Sharma, G. T. Fong. Patterns of smoking among adolescents in Malaysia and Thailand: findings from the International Tobacco Control Southeast Asia Survey. Asia Pacific Journal of Public Health, 20 (3) (2008) 193-203. DOI: https://doi. org/10.1177/1010539508317572

[11] F. R. Johnson, E. Lancsar, D. Marshall, V. Kilambi, A. Mühlbacher, D. A. Regier, J. F. Bridges. Constructing experimental designs for discrete-choice experiments: report of the ISPOR conjoint analysis experimental design good research practices task force .Value in health, 16 (1) (2013) 3-13. DOI: https://doi.or $\mathrm{g} / 10.1016 / \mathrm{j} . \mathrm{jval} .2012 .08 .2223$

[12] S. Brotman, B. Ryan, R. Cormier. The health and social service needs of gay and lesbian elders and their families in Canada. The Gerontologist, 43 (2) (2003) 192-202. DOI: https://doi.org/10.1093/geront/43.2.192

[13] B. E. Ashforth, R. H. Humphrey. Emotional labor in service roles: The influence of identity. Academy of management review, 18 (1) (1993) 88-115. DOI: https: //doi.org/10.5465/amr.1993.3997508 
[14] S. Green, C. Davis, E. Karshmer, P. Marsh, B. Straight. Living stigma: The impact of labeling, stereotyping, separation, status loss, and discrimination in the lives of individuals with disabilities and their families. Sociological Inquiry, 75 (2) (2005) 197-215. DOI: https://doi.org/10.1111/j.1475-682X.2005.00119 .X

[15] I. H. Meyer. Why lesbian, gay, bisexual, and transgender public health?. American Journal of Public Health, 91 (6) (2001) 856. DOI: https://doi.org/10.2105/ ajph.91.6.856

[16] V. Priola, D. Lasio, S. De Simone, F. Serri. The sound of silence. Lesbian, gay, bisexual and transgender discrimination in inclusive organizations .British Journal of Management, 25 (3) (2014) 488-502. DOI: https://doi.org/10.1111/1467-8551.12043

[17] J. Habermas. Religion in the public sphere. European journal of philosophy, 14 (1) (2006) $1-25$.

[18] T. R. Burns, T. Dietz. Cultural evolution: Social rule systems, selection and human agency. International Sociology, 7 (3) (1992) 259-283. DOI: https://doi.org/ $10.1177 / 026858092007003001$

[19] L. O. Kallings. The first postmodern pandemic: 25 years of HIV/AIDS. Journal of internal medicine, 263 (3) (2008) 218-243. DOI: https://doi.org/10.1111/j.1365 $-2796.2007 .01910 . x$

[20] A. M. Meer Ahmad. The Control and Prevention of HIV/AIDS in Malaysia. Allergy drugs clin immunol 3: 115. Allergy drugs clin immunol, 3 (1) (2019) 72-86.

[21] M. M. Philbin, J. S. Hirsch, P. A. Wilson, A. T. Ly, L. M. Giang, R. G. Parker. Structural barriers to HIV prevention among men who have sex with men (MSM) in Vietnam: diversity, stigma, and healthcare access. PLoS One, 13 (4) (2018) e0195000. DOI: https: //doi.org/10.1371/journal.pone.0195000

[22] D. C. Des Jarlais, C. McKnight, C. Goldblatt, D. Purchase. Doing harm reduction better: syringe exchange in the United States. Addiction, 104 (9) (2009) 1441-1446. DOI: https://doi.org/10.1111/j.1360 $-0443.2008 .02465 . x$

[23] G. A. Marlatt, K. Witkiewitz. Update on harmreduction policy and intervention research. Annual Review of Clinical Psychology, 6 (2010) 591-606. DOI: https://doi.org/10.1146/annurev.clinpsy.121208.131438
[24] T. Measham, J. Guzder, C. Rousseau, L. Pacione, M. Blais-McPherson, L. Nadeau. Refugee children and their families: Supporting psychological well-being and positive adaptation following migration. Current problems in pediatric and adolescent health care, 44 (7) (2014) 208-215. DOI: https://doi.org/10.1016/j.cppeds. 2014.03.005

[25] S. Vega, H. G. Crawford, J. L. Van Pelt. Safe schools for LGBTQI students: How do teachers view their role in promoting safe schools?. Equity \& Excellence in Education, 45 (2) (2012) 250-260. DOI: https://doi.org/10.1080/10665684.2012.671095

[26] A. J. Daley, J. L. Duda. Self-determination, stage of readiness to change for exercise, and frequency of physical activity in young people. European Journal of Sport Science, 6 (4) (2006) 231-243. DOI: https://doi.o $\mathrm{rg} / 10.1080 / 17461390601012637$ 